\title{
Role of a Lipopolysaccharide Gene for Immunogenicity of the Enterobacterial Common Antigen
}

\author{
G. SCHMIDT,* D. MANNEL, H. MAYER, H. Y. WHANG, AND E. NETER \\ Max-Planck-Institut für Immunbiologie, D-78 Freiburg i.Br., Germany, ${ }^{*}$ and Departments of Pediatrics and \\ Microbiology, School of Medicine, State University of New York at Buffalo, Buffalo, New York 14222
}

Received for publication 27 November 1975

It is known that only certain strains of the family of Enterobacteriaceae, notably rough $(\mathrm{R})$ mutants with the type $\mathrm{R} 1$ or $\mathrm{R} 4$ core, evoke antibodies in high titers against the common enterobacterial antigen (CA) after immunization of rabbits with heated cell suspensions. The present investigation deals with genetic and immunochemical aspects of certain R1 and R4 mutants isolated from Escherichia coli 08 and various Shigella serotypes which, unexpectedly, do not induce CA antibody formation. Immunochemical and genetical (transduction and conjugation) experiments revealed that the rough phenotype of these special mutants was evoked by a mutation of a pyrE-linked $r f a$ gene, called $r f a L$, which is involved in translocation of O-specific polysaccharides onto the lipopolysaccharide core. The transduction of the defective $r f a L$ allele into appropriate rough recipients results in transductants which have simultaneously lost the ability to evoke CA antibodies. This finding suggests that a close connection exists between the function of the $r f a L$ gene and the expression of CA immunogenicity in R1 and R4 mutants. One of the strains synthesized neither O-hapten nor CA, suggesting a mutation in a region equivalent to the rfe genes of Salmonella.

Since the discovery by means of the hemagglutination test of the enterobacterial common antigen (CA) by Kunin et al. (5), it has been known that, although almost all wild-type strains of Enterobacteriaceae produce this antigenic determinant, only a few, notably Escherichia coli O14, evoke CA antibodies in high titers in rabbits. This unique feature of $E$. coli O14 is particularly evident when heated cell suspensions or supernatants thereof are used for immunization. When viable cell suspensions are employed for immunization certain other strains elicit CA antibody formation, although to a lesser extent than $E$. coli $O 14$ (24). In this presentation CA immunogenicity is defined as the ability of heated suspensions to evoke CA antibodies in the rabbit upon intravenous injection; CA antigenicity is defined as the capacity of the material to specifically inhibit hemagglutination of CA-modified erythrocytes by CA antibodies and to modify erythrocytes for agglutination by CA antibodies.

Investigations into the nature of immunogenicity revealed that with rough $(R)$ mutants of $E$. coli, CA immunogenicity is closely related to the type of the lipopolysaccharide (LPS) core $(11,21)$. So far as the hitherto known LPS core types are concerned, the following information is relevant. In the LPS molecule the basal core oligosaccharide is the connecting link between the lipid part and the highly variable $\mathrm{O}$-specific polysaccharides (7). The LPS core is less variable than the polysaccharide side chains and, so far as is known at this time, is identical in all Salmonella serotypes. In $E$. coli five different complete core regions, designated as $\mathrm{R} 1$ to $\mathrm{R} 4$ and $\mathrm{K}-12$ (represented by $E$. coli $\mathrm{K}-12$ ) have so far been identified $(17-19,21)$. It is of interest to note that the R1, R3, and R4 LPS core types have also been found in certain Shigella serotypes (12). So far as $E$. coli $\mathrm{O} 14$ is concerned, recent investigations with the 014 test strain and other strains typed as $\mathrm{O} 14$ have revealed that these CA-immunogenic strains do not represent smooth $O$ serotypes; rather, they are encapsulated (K7 antigen) rough strains with the complete LPS core of the R4 type (21). Additional studies have revealed that rough $\mathrm{mu}$ tants of $E$. coli with the complete R1 LPS core also provoke CA antibody formation, in contrast to the smooth parent strains and rough mutants with incomplete core $(11,24)$. On the other hand, rough mutants of $E$. coli which have the R2 or R3 core as well as rough mutants of Salmonella with the $\mathrm{Ra}$ core type fail to engender CA antibodies. These nonimmunogenic strains, however, have the CA determinant, as demonstrated by means of the hemagglutination and hemagglutination-inhibition tests. Thus, it became evident that, for CA to be 
immunogenic among rough mutants, the LPS core types R1 or the serologically related R4 are essential. Recently, it was shown that $E$. coli $\mathrm{K}-12$, a rough strain, also evoked CA antibodies (unpublished observation).

The present investigation is concerned with the CA immunogenicity of various Shigella and $E$. coli rough mutants with the R1 or R4 core, respectively, which, contrary to expectation, fail to evoke CA antibodies. It is shown that the lack of CA immunogenicity is due to defects in a gene involved in LPS synthesis.

\section{MATERIALS AND METHODS}

Bacteria. The bacterial strains used in this study are listed in Table 1 . The smooth (O8) $E$. coli Hfr59 strain used as donor transfers its chromosome in a counterclockwise direction with the histidine operon (his) as a leading locus (19). E. coli F947, used as recipient in $\mathrm{P} 1$ transductions, is a pyrE $E^{-}$mutant of $E$. coli $F 870$, a rough derivative from $E$. coli 08 . The strain F947 synthesizes a K-12 core as the result of the introduction of $r f a$ genes from an $E$. coli K-12 Hfr donor, as described previously (17). The rough phenotype of $\mathrm{F} 947$ originates from a defective rfb region which blocks the synthesis of 08-specific polysaccharides. Additional markers of $E$. coli F947 include defects in histidine (his ${ }^{-}$) and methionine (met ${ }^{-}$) synthesis and resistance to streptomycin $(s t r)$. The other strains listed in Table 1 represent rough mutants which are the subject of the present investigations.

Culture media. As solid complete medium $\mathrm{D}_{1,5^{-}}$ agar (16) with $0.3 \%$ glucose and $1.5 \%$ agar and as fluid medium Standard I broth (E. Merck, AG, Darmstadt, Germany) were used. For the selection of transductants and recombinants Davis minimal agar (6) with $0.3 \%$ glucose and, when necessary, supplemented with appropriate amino acids $(20 \mu \mathrm{g} /$ $\mathrm{ml}$ ) was employed. For propagation of $\mathrm{P} 1 k c$ phage and transduction the following medium was used: tryptose (Difco Laboratories, Detroit, Mich.), $10 \mathrm{~g}$; Difco yeast extract, $5 \mathrm{~g} ; \mathrm{NaCl}, 8 \mathrm{~g}$; glucose, $1 \mathrm{~g}$; and
$1,000 \mathrm{ml}$ of distilled water. This medium was supplemented with calcium chloride to $5 \times 10^{-3} \mathrm{M}$. When used as solid medium $15 \mathrm{~g}$ of agar was added to 1,000 ml.

Transduction. For transduction experiments we used phage $\mathrm{P} 1 k c$, a derivative of $\mathrm{P} 1$. Phage $\mathrm{P} 1 k c$ lysates were prepared on the respective donor strains, using the agar layer method described by Adams (1). The resulting phage lysates usually contained approximately $10^{10}$ plaque-forming units.

For transduction overnight broth cultures of the recipients were diluted 20 -fold in broth with calcium chloride and incubated at $37 \mathrm{C}$ in a shaking water bath for $4 \mathrm{~h}$. Equal volumes of broth culture and $\mathrm{P} 1 k c$ lysate were mixed to give a multiplicity of nearly 1. After incubation at $37 \mathrm{C}$ for $20 \mathrm{~min}, 0.1-\mathrm{ml}$ samples were plated on appropriately supplemented selective agar and incubated for $48 \mathrm{~h}$ at $37 \mathrm{C}$. Transductants were transferred first onto selective medium and then streaked on complete agar for singlecolony isolation. The purified transductants were tested for unselected markers.

Bacteriophages. The rough-specific phages U3, C21, and 6SR were used to determine the LPS core present in transductants. Phage U3 (23) lyses specifically cells with the $E$. coli $\mathrm{K}-12$ core, whereas phages 6SR and C21 are active on rough strains with the $R 1$ core $(17,19)$. The phages were propagated on their respective hosts as described previously (17).

Conjugation. Freshly grown suspensions of donor and recipient cells were mixed in broth in amounts to yield approximately $5 \times 10^{7}$ donor and $5 \times 10^{8}$ recipient cells. After a 2-h incubation at $37 \mathrm{C}$ aliquots of $0.1 \mathrm{ml}$ of suitable dilutions were plated on appropriately supplemented minimal agar containing $100 \mu \mathrm{g}$ of streptomycin per $\mathrm{ml}$ for counterselection of the streptomycin-sensitive donor $E$. coli Hfr59. After incubation at $37 \mathrm{C}$ for $48 \mathrm{~h}$ recombinants were first transferred onto the selection agar and then streaked on complete agar from which single colonies were isolated. The recombinants were screened by slide agglutination in $3.5 \%$ saline and in anti- $E$. coli 08 serum (diluted 1:20 in $0.2 \%$ saline to prevent spontaneous agglutination of rough mutants).

TABLE 1. Bacterial strains

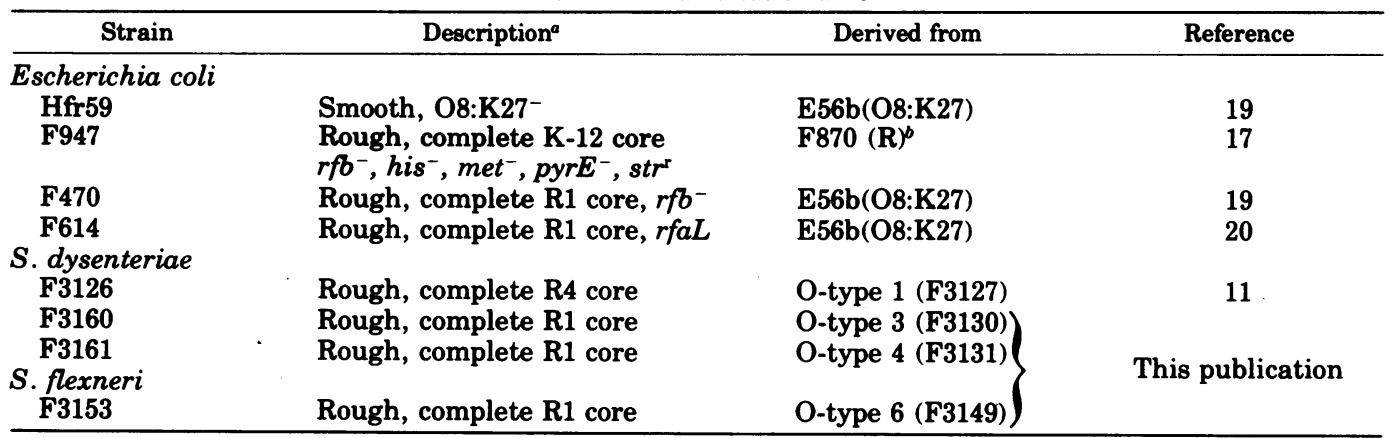

${ }^{a}$ Gene symbols: $r f a$ and $r f b$, genes participating in the biosynthesis of lipopolysaccharide; his, histidine; met, methionine; pyr, pyrimidine; str $r^{\text {, }}$ resistance to streptomycin.

${ }^{b}$ F870, a rough mutant $\left(r \mathrm{fb}^{-}\right)$of $E$. coli 08 , synthesizes a K-12 LPS core, due to the introduction of $r f a$ genes from the $E$. coli K-12 Hfr donor W1895 (17). 
Isolation and chemical analyses of LPS. LPS of Shigella $\mathbf{R}$ mutants was isolated by the extraction procedure of Galanos et al. (3) with a mixture of phenol-chloroform-light petroleum ether. The aldoses were liberated by acid hydrolysis with $0.1 \mathrm{~N}$ $\mathrm{HCl}$ for $48 \mathrm{~h}$ at $100 \mathrm{C}$ and converted into the alditol acetate derivatives (14) for gas-liquid chromatography. The samples were injected as chloroform solutions into a Varian aerograph (model 1520 B) fitted with a metal column $(0.32$ by $152 \mathrm{~cm})$ at column temperatures of 165 to $175 \mathrm{C}$. Xylitol pentaacetate was used as reference compound for quantitation (19).

Bacteria grown on $D_{1,5}$-agar (16) and preextracted with phenol-chloroform-petroleum ether were subsequently treated with hot phenol-water for extraction of the phenol-chloroform-petroleum ether-insoluble $\mathrm{O}$-specific hapten. The resulting aqueous phase contains, in addition to the bulk of ribonucleic acid, residual R LPS and, in certain instances, 0 -specific hapten and glucan. Ultracentrifugation $(105,000 \times$ $g, 4 \mathrm{~h}$ ) removes LPS, whereas ribonucleic acid and O-specific hapten remain in the supernatant fraction $\left(L_{1}-G R, 12\right)$. The presence of the respective $O$ specific hapten was then examined by serological methods, e.g., by immunoelectrophoresis with the respective $\mathrm{O}$ serum.

Serological methods: detection of $\mathbf{O}$-specific hapten. Agar gel electrophoresis was carried out by the micro-method of Scheidegger (15), using an electrophoresis chamber (Gelman Instrument Company, Ann Arbor, Mich.) and diethylbarbituric acid-sodium veronal-calcium lactate buffer (4) at $10 \mathrm{~V} / \mathrm{cm}$ for $1 \mathrm{~h}$. The $\mathrm{L}_{1}-\mathrm{GR}$ lyophilisate was dissolved as a $1 \%$ solution in saline, and $5 \mu \mathrm{g}$ was filled into the antigen well of the agar layer. Undiluted rabbit antiserum against the corresponding $S$ form was placed into the antiserum trough. Precipitation arcs were read after incubation for $24 \mathrm{~h}$ at $4 \mathrm{C}$.

CA determination. The presence of CA was determined by the hemagglutination test as reported in detail previously $(24,25)$. Briefly, the strains were grown on $60 \mathrm{ml}$ of brain veal agar in Kolle flasks for $18 \mathrm{~h}$ at $37 \mathrm{C}$, and the resulting growth was suspended in $25 \mathrm{ml}$ of phosphate hemagglutination buffer (pH 7.3; Difco) per Kolle flask. The supernatant of the suspension, after heating at $100 \mathrm{C}$ for $1 \mathrm{~h}$ and centrifugation at $23,500 \times g$ for $20 \mathrm{~min}$, was used for modification of erythrocytes. A $2.5 \%$ rabbit erythrocyte suspension was washed three times in phosphate hemagglutination buffer. The above antigen preparation was added to the sediment in amounts sufficient to restore the erythrocyte concentration of $2.5 \%$. The antigen-erythrocyte mixture was incubated in a water bath at $37 \mathrm{C}$ for $30 \mathrm{~min}$, and the erythrocytes were washed to remove excess antigen. CA antiserum in twofold serial dilutions $(0.2 \mathrm{ml})$ was mixed with an equal volume of antigenically modified rabbit erythrocytes. The mixtures were incubated in a water bath at $37 \mathrm{C}$ for $30 \mathrm{~min}$, and the resulting hemagglutination was read grossly after centrifugation at $1,300 \times g$ for $2 \mathrm{~min}$. Hemagglutination in titers similar to those obtained with a known CA antigen were considered as tentative evidence for the presence of $\mathrm{CA}$. Confirmation was obtained in hemagglutination-inhibition tests, in which the supernatant of the culture under investigation was mixed with the CA antiserum, the latter in twofold serial dilutions. The mixtures were incubated for $30 \mathrm{~min}$ at $37 \mathrm{C}$, erythrocytes modified with the ethanol-soluble semipurified CA obtained from $S$. typhimurium were then added, and the hemagglutination test was completed as above. Reduction of the antibody titer by at least $75 \%$ was considered to be evidence of the presence of CA.

Immunization. To determine whether the strains under investigation evoked CA antibodies in rabbits, the following immunization schedule was used, as described previously (24). Groups of three New Zealand white rabbits were immunized intravenously with the heated $(100 \mathrm{C}, 1 \mathrm{~h})$ bacterial suspension (approximately $10^{9}$ cells $/ \mathrm{ml}$ ) harvested from a Kolle flask with brain veal agar in $25 \mathrm{ml}$ of hemagglutination buffer. On days 0,3 , and $7,1 \mathrm{ml}$ of the suspension in a dilution of $1: 100$ was injected, and on day 10 $1 \mathrm{ml}$ of a dilution of 1:10 was injected. Blood samples were obtained prior to immunization and on days 7 , 10 , and 14 following initiation of immunization. The sera were kept frozen at $-20 \mathrm{C}$ until use.

Titration of CA antibodies. As described previously $(24,25)$, sera were titrated for the presence of CA antibodies in serial twofold dilutions and in amounts of $0.2 \mathrm{ml}$. To the serum samples were added equal amounts of erythrocytes modified by CA (ethanol-soluble fraction of $S$. typhimurium). The hemagglutination test was completed, and the specificity of the CA antibodies was confirmed by hemagglutination-inhibition tests as described above.

\section{RESULTS}

Characterization of rough mutants. The rough strains $E$. coli F470 and F614 (20) and Shigella dysenteriae F3126 (12) have been described previously. Their LPS cores belong to the R1 (F470, F614) and R4 (F3126) types indicated in Table 3 . The other three Shigella $\mathrm{R}$ mutants listed in Table 1 were isolated as roughlooking colonies during cultivation of the respective smooth parent strains on nutrient agar. These mutants were purified by repeated isolation of single colonies. The purified isolants had the characteristics of typical $R$ mutants, growing in fluid medium with a heavy sediment and agglutinating spontaneously in $3.5 \%$ saline solution. The core type of each of the three newly isolated Shigella rough mutants was identified by comparison with standard core type mutants using the same serologic methods (passive hemagglutination, serum absorption) as described previously (12). Thus, it could be shown that in passive hemagglutination tests LPS from F3160, F3161, and F3153 strongly reacted with a standard R1 antiserum and that the cells of these strains completely absorbed the hemagglutinating antibodies of antiserum prepared against the homologous $\mathrm{R} 1$ test strain. 
Conversely, cells of the $E$. coli R1 prototype strain (F470) completely removed the antibodies against the three Shigella $\mathrm{R}$ mutants. The outcome of the serologic tests thus demonstrated the presence of an R1 LPS core in the rough Shigella strains F3160, F3161, and F3153.

The quantitative sugar composition of the core oligosaccharides of the various Shigella rough mutants was determined (Table 2). A comparison of the values for the different strains shown in Table 2 with those of the previously established $R 1$ core type mutant F470 suggests the presence of a R1 core in F3160, F3161, and F3153. Thus, the results of chemical analyses are consistent with those of the serologic tests.

CA and its immunogenicity. None of the antisera produced against cells of the four rough Shigella mutants listed in Table 1 contain CA antibodies. Nevertheless, as shown by serologic determination analysis, the rough mutants, with the exception of Shigella F3160, can synthesize CA (Table 3). The lack of CA synthesis by F3160 explains the absence of CA immunogenicity. On the other hand, the nonimmunogenicity of CA in the Shigella R1 and R4 mutants (F3126, F3153, F3161) was unexpected, since certain $E$. coli mutants of these core types evoke CA antibodies in high titers.
Recent observations, however, have revealed that $E$. coli R1 mutants may be non-immunogenic with regard to $\mathrm{CA}$. Thus, the $E$. coli $\mathrm{R} 1$ mutants F470 and F614, both derived from wild-type $E$. coli E56b (O8), differ in their CA immunogenicity: F470 evokes CA antibodies and F614 does not (11). The genetical analysis of both these strains has shown that different genetic defects have led to the same rough phenotype, namely, rough mutants with the complete R1 core. In $E$. coli $\mathrm{F} 470$ the S/R mutation site is located within the his-linked $r f b$ region, which controls the synthesis of the O-specific polysaccharides. The rough phenotype of F614 is caused by a defect of a mtl-linked gene (20), which is involved in the translocation of O-specific polysaccharides onto the complete core. This gene is apparently part of a cluster of different $r f a$ genes responsible for core synthesis (20). Its equivalent in Salmonella is designated as $r f a L$ (22). Defects in the $r f b$ genes (block of O-chain synthesis) or in the $r f a L$ gene result in the same rough phenotype, namely, rough mutants with a complete core. Mutants with a defective $r f a L$ gene but otherwise intact rf genes accumulate $\mathrm{O}$-specific chains (O-hapten), which can be detected by immunoelectrophoretic methods using O-specific antisera (see Materials and Methods). The Shigella R1 mu-

TABLE 2. Sugar composition of LPS from Shigella $R$ mutants ${ }^{a}$

\begin{tabular}{lccccc}
\hline \multirow{2}{*}{ Strain } & \multicolumn{5}{c}{ Molar ratios of neutral sugars (galactose = 2.0) } \\
\cline { 2 - 6 } & Galactose & Glucose & Heptose & KDO & GlcN \\
\hline F3160 & 2.0 & 3.3 & 3.5 & + & + \\
F3161 & 2.0 & 3.5 & 2.4 & + & + \\
F3153 & 2.0 & 3.3 & 2.4 & + & + \\
F470 R1 prototype & 2.0 & 3.0 & 2.9 & + & + \\
\hline
\end{tabular}

${ }^{a}$ GlcN is only present in the lipid A moiety, but not in the core oligosaccharide. Abbreviations: KDO, 2Keto-3-deoxy-octonate; GlcN, D-glucosamine. Symbol: (+) present.

TABLE 3. Characterization of different $E$. coli and Shigella rough mutants

\begin{tabular}{|c|c|c|c|c|c|}
\hline Strain & $R$ core type & $\mathbf{C A}^{a}$ & $\mathbf{C A}_{\mathrm{im}}{ }^{b}$ & O hapten ${ }^{c}$ & Genetic defect assumed \\
\hline \multicolumn{6}{|l|}{ E. coli } \\
\hline F470 & R1 & + & + & - & $r f b$ \\
\hline F614 & $\mathrm{R} 1$ & + & - & + & $r f a L$ \\
\hline \multicolumn{6}{|c|}{ S. dysenteriae } \\
\hline F3126 & R4 & + & - & - & $r f a L$ \\
\hline F3160 & R1 & - & - & - & rfe \\
\hline F3161 & R1 & + & - & + & $r f a L$ \\
\hline \multicolumn{6}{|l|}{ S. flexneri } \\
\hline F3153 & R1 & + & - & + & $r f a L$ \\
\hline
\end{tabular}

\footnotetext{
${ }^{a}$ Symbols: (+) Presence of enterobacterial common antigen (CA) as tested by passive hemagglutination; (-) absence of enterobacterial common antigen (CA) as tested by passive hemagglutination.

${ }^{b} \mathrm{CA}_{\mathrm{im}}$, Immunogenic $\mathrm{CA}$ as tested by immunization of rabbits.

c Symbols: (+) Precipitation of aqueous solutions of $\mathrm{L}_{1}$-GR fraction (O hapten) with specific O-antisera; (-) no precipitation. O hapten is uncharged in F614 but negatively charged in F3161 and F3153. This agrees with recent results of Dmitriev et al. (2).
} 
tants, with the exception of F3160, can synthesize 0 -specific hapten (Table 3 ). They are considered, therefore, to have a defect in the translocation system for $\mathrm{O}$-specific polysaccharides similar to that of $E$. coli F614.

The simultaneous lack of O-hapten and of CA in Shigella F3160 may be the result of a defect in a gene region which is equivalent to the ilvlinked rfe gene cluster found in Salmonella (8). These rfe genes participate in CA synthesis and are required also for the production of $\mathrm{O}$-specific chains in certain serotypes of Salmonella $(9$, 10). The characteristics of the different rough mutants are presented in Table 3.

In the R4 mutant F3126 O-specific hapten could not be demonstrated. We assume, therefore, that this strain either carries a defect additional to a $r f a L$ mutation (e.g., an $r f b$ defect) or hitherto unknown mutation(s).

Genetic experiments. Transduction. The results summarized in Table 3 suggest that the inability to evoke CA antibodies of $E$. coli F614 as well as of F3153 (R1) and F3161 (R1) appears to be closely connected with a certain mutation in the LPS synthesis presumably due to a defective gene termed $r f a L$ according to nomenclature of Salmonella genetics (22).

In unpublished experiments it was shown that, as in Salmonella, in E. coli and in Shigella as well, core ( $r f a)$ genes are cotransducible with $p y r E$ by the transducing phage $\mathrm{P} 1 k c$. This suggested that, analogous to Salmonella, a cluster of $r f a$ genes presumably harboring the $r f a L$ gene is located in this region. The general plan of our transduction experiments was to transfer the $p y r E$-linked $r f a$ cluster of the above-mentioned $\mathbf{R}$ mutants into appropriate recipients. Examination of the transductants should elucidate whether they have obtained the S/R mutation site (presumably $r f a L$ ) of the donors and simultaneously have become nonimmunogenic with regard to CA.

The above-mentioned strains were susceptible to phage P1kc and thus suitable for transductions. E. coli F470 and the smooth parents of F3153 and F3161, Shigella flexneri type 6 (F3149) and Shigella dysenteriae type 4 (F3131), respectively, were also $\mathrm{P} 1 k c$ sensitive and were included in the transduction experiments for control purposes as donors with intact rfa genes.

The transducing phage $\mathrm{P} 1 k c$ was propagated on each of these strains. As recipient the rough E. coli F947 ( $\left.r \mathrm{fb}^{-}, \mathrm{pyrE}^{-}\right)$strain which has the K-12 core (see Materials and Methods) was used. From mixtures of each P1 lysate and the recipient F947 pyrE ${ }^{+}$transductants were selected on appropriate selective media. After single-colony purification the transductants were tested for unselected markers. Their core type (R1 or K-12) was inferred from their sensitivity patterns to appropriate phages. Thus, pyrE $E^{+}$transductants, which inherited the $r f a$ genes for $\mathrm{R} 1$ core synthesis, should be sensitive to phages $\mathrm{C} 21$ and 6SR but resistant to the K12-specific phage U3. Conversely, the K-12 core should be detected by the sensitivity of the transductants to phage U3 and resistance to phages C21 and 6SR (17). The results of the transduction experiments with each of the six donors are presented in Table 4. According to the phage reaction patterns a considerable portion of the transductants synthesize the $R 1$ core in consequence of cotransduced donor $r f a$ genes. All transductants had retained the auxotrophic markers for histidine and methionine.

LPS extracted from the R1-like transductants F2812 and F2688 were used in passive hemagglutination tests with R1 and K-12 antisera. For comparison the results with LPS of R1 strains and the $\mathrm{K}-12$ recipient are included (Table 5). The results of the hemagglutination tests showed that the R1 transductants derived from smooth and rough Shigella donors, respectively, synthesize LPS which are serologically identical with that of the prototype R1 mutant $E$. coli F470. The serological results were confirmed by quantitative sugar analyses of LPS isolated from different $\mathrm{R} 1$ transductants.

CA immunogenicity of transductants. Selected pyrE ${ }^{+}$transductants, having received $r f a$ genes from different donors for the R1 core synthesis or still having the recipient K-12 core, were used for immunization of rabbits. The antisera were tested for the presence of CA antibodies. The results given in Table 6 show that those transductants which received the

TABLE 4. Inheritance of rfa genes of different donors (R1) in P1 transduction of pyrE $E^{+}$to recipient $E$. coli F947 $(K-12)^{a}$

\begin{tabular}{|c|c|c|c|c|}
\hline \multirow{2}{*}{$\begin{array}{l}\text { pyrE } E^{+} \text {se- } \\
\text { lected from } \\
\text { donor }\end{array}$} & \multirow{2}{*}{$\begin{array}{l}\text { Total no. of } \\
\text { transduc- } \\
\text { tants tested }\end{array}$} & \multicolumn{2}{|c|}{$\begin{array}{l}\text { No. of transduc- } \\
\text { tants with core }\end{array}$} & \multirow{2}{*}{$\begin{array}{l}\text { Transfer } \\
\text { frequency } \\
\text { of donor } \\
\text { rfa genes } \\
\text { (\%) }\end{array}$} \\
\hline & & K-12 & $\mathbf{R} \mathbf{1}$ & \\
\hline F470 & 123 & 71 & 52 & 42 \\
\hline F614 & 56 & 31 & 25 & 45 \\
\hline F3131 & 50 & 41 & 9 & 18 \\
\hline F3161 & 48 & 35 & 13 & 27 \\
\hline F3149 & 49 & 39 & 10 & 20 \\
\hline F3153 & 50 & 38 & 12 & 24 \\
\hline
\end{tabular}

a Sensitivity to phages 6 SR and C21 indicates the presence of the $R 1$ core resulting from a transfer of the donor rfa genes. Sensitivity to phage U3 was taken as evidence for the presence of the recipient K-12 core. 
unselected rfa genes of $E$. coli F614 (F1027, F1028), Shigella F3153 (F2868), or Shigella F3161 (F2688) do not evoke CA antibodies. This indicates that the non-immunogenicity of CA of these strains is indeed closely connected with a mutation within the pyrE-linked rfa cluster. The transductant F2689 retained its CA immunogenicity because $r f a$ genes of the non-immunogenic donor (F3161) were not cotransduced with $p y r E$.

To ascertain whether this mutation concerns the $r f a L$ allele in the respective transductants, we performed conjugation experiments with an appropriate $E$. coli Hrf donor.

Conjugation experiments. The above-mentioned transductants and their parental recipient $E$. coli F947 possess a defective $r f b$ region and consequently cannot produce O-specific polysaccharides. Therefore, the introduction of the his-linked $r f b$ region of a smooth donor into transductants with intact $r f a L$ genes should result in smooth hybrids with the donor's $\mathrm{O}$

TABLE 5. Passive hemagglutination of erythrocytes coated with different $R$ LPS

\begin{tabular}{lcc}
\hline \multirow{2}{*}{ R LPS source } & \multicolumn{2}{c}{ Reciprocal titers in antisera ${ }^{a}$} \\
\cline { 2 - 3 } & $\mathrm{R} 1$ & $\mathrm{~K}-12$ \\
\hline Parents & & \\
F470 (R1) & 2,560 & $<20$ \\
F3161 (R1) & 5,120 & $<20$ \\
F947 (K-12) & $<20$ & 640 \\
Transductants & 5,120 & $<20$ \\
F2812 (R1) & & $<20$ \\
F2688 (R1) & 2,560 & \\
\hline${ }^{a}$ CA antibodies absorbed previously with Salmo- \\
nella greenside. \\
${ }^{b}$ rfa genes are from $S$. dysenteriae type 4 F3131 \\
(S). \\
${ }^{c}$ rfa genes are from $S$. dysenteriae F3161 (R).
\end{tabular}

specificity. In case the recipients have mutated $r f a L$ genes, the resulting hybrids should retain the rough phenotype.

As donor we used $E$. coli $\mathrm{Hfr} 59$ (08) and used as recipients different transductants with the $\mathrm{R} 1$ core, including those which are assumed to have intact $r f a L$ genes, e.g., CA immunogenic transductants derived from donors $E$. coli $\mathbf{F 4 7 0}$, Shigella F3131, and Shigella F3149, respectively.

From each mating mixture of the donor with different recipients, $50 \mathrm{his}^{+} \mathrm{str}^{\mathrm{r}}$ recombinants were selected on minimal agar supplemented with methionine and streptomycin. After repeated single-colony purification the recombinants of the crosses with the CA non-immunogenic recipient strains F1027, F2688, and F2868 were not able to express $E$. coli 08 specificity, although they can synthesize O8-specific hapten genic recipient strains F1027, F2688, and F2868 were not able to express $E$. coli 08 specificity, although they can synthesize 08 -specific hapten demonstrable by agar precipitation methods, as evident from the study of some of the recombinants. Thus, it is assumed that the three abovementioned recipients, and consequently the $h_{i s}{ }^{+}$hybrids thereof, possess a defective $r f a L$ allele previously transferred by transduction from E. coli F614 and Shigella F3161 and F3153, respectively, into $E$. coli F947. On the other hand, most of the recombinants of the crosses with the CA-immunogenic transductants F1041, F2812, and F2867 showed O8 specificity in consequence of the introduction of the hislinked $r f b$ regions. Therefore, these recipients must have intact $r f a L$ genes.

The interpretation of the results of the genetic experiments leads to the suggestion that a mutation of the rfaL gene is the cause for non-

TABLE 6. CA antibody titer of antisera against different pyrE ${ }^{+}$transductants and the recipient F947 (K-12)

\begin{tabular}{|c|c|c|c|}
\hline \multicolumn{3}{|c|}{ Antiserum against } & \multirow{2}{*}{$\begin{array}{l}\text { Reciprocal CA anti- } \\
\text { body titer }\end{array}$} \\
\hline Strain & $\begin{array}{c}\text { Donor } r f a \\
\text { genes }(\mathrm{R} 1)^{a}\end{array}$ & Genes from donor & \\
\hline \multicolumn{4}{|c|}{ Transductants } \\
\hline F1041 & + & F470 E. coli $\mathrm{O} 8\left(r f a L^{+}\right)$ & 2,560 \\
\hline F1027 & + & F614 E. coli O8 ( $\left.\mathrm{rfaL}^{-}\right)$ & $<10$ \\
\hline F1028 & + & F614 E. coli O8 ( $\left.r f a L^{-}\right)$ & $<10$ \\
\hline F2812 & + & F3131 S. dysenteriae type $4\left(r f a L^{+}\right)$ & 1,280 \\
\hline F2813 & - & F3131 S. dysenteriae type $4\left(r f a L^{+}\right)$ & 640 \\
\hline F2688 & + & F3161 S. dysenteriae type $4\left(r f a L^{-}\right)$ & $<10$ \\
\hline F2689 & - & F3161 S. dysenteriae type $4\left(r f a L^{-}\right)$ & 320 \\
\hline F2867 & + & F3149 S. dysenteriae type $6\left(r f a L^{+}\right)$ & 640 \\
\hline F2868 & + & F3153 S. dysenteriae type 6 ( $\left.r f a L^{-}\right)$ & $<10$ \\
\hline \multicolumn{4}{|l|}{ Recipient } \\
\hline F947 & - & - & 160 \\
\hline
\end{tabular}

${ }^{a}$ Symbols: (+) present; (-) absent. 
TABLE 7. Serological analysis of his ${ }^{+}$recombinants from crosses between $\mathrm{E}$. coli $\mathrm{H}$ fr59 (O8) and different recipients

\begin{tabular}{|c|c|c|c|c|}
\hline \multicolumn{3}{|c|}{ Recipients } & \multicolumn{2}{|c|}{$\begin{array}{l}\text { No. of } \text { his }^{+} \text {re- } \\
\text { combinants with } \\
\text { phenotype }\end{array}$} \\
\hline $\begin{array}{l}\text { Strain } \\
\text { no. }\end{array}$ & $\mathrm{CA}_{\mathrm{im}}{ }^{a}$ & $\begin{array}{l}\text { Transductant } \\
\text { from donor }\end{array}$ & $\begin{array}{c}\text { Smooth } \\
\mathrm{O8}^{+}\end{array}$ & $\begin{array}{l}\text { Rough } \\
\text { O8 }^{-}\end{array}$ \\
\hline F1027 & - & F614 & 0 & 50 \\
\hline F1041 & + & F470 & 46 & 4 \\
\hline F2688 & - & F3161 & 0 & 50 \\
\hline F2812 & + & F3131 & 48 & 2 \\
\hline F2868 & - & F3153 & 0 & 50 \\
\hline F2867 & + & F3149 & 45 & 5 \\
\hline
\end{tabular}

${ }^{a}$ Immunogenic CA. Symbols: (+) injection of heated cells into rabbits does evoke CA antibodies; (-) injection of heated cells into rabbits does not evoke CA antibodies.

${ }^{b}$ Smooth $\mathrm{O8}^{+}$is agglutinable in 08 antiserum and non-agglutinable in $3.5 \%$ saline. Rough $\mathrm{Or}^{-}$is nonagglutinable in $\mathrm{O} 8$ antiserum and agglutinable in $3.5 \%$ saline.

immunogenicity of the CA in cells of $E$. coli F614, Shigella F3161, and Shigella F3153. The genetic defect of Shigella F3126 could not be mapped because the transducing phage P1 could not be grown on this mutant. Further experiments are needed to prove whether in this strain a similar relation exists between $S / R$ mutation and non-immunogenicity of CA.

\section{DISCUSSION}

It has been shown recently that $\mathrm{CA}$ antibodies in high titers are evoked in rabbits by rough mutants having the R1 or R4 LPS core $(11,24)$, even when heated suspensions are used for immunization. It was, therefore, an unexpected finding that one $E$. coli R1 mutant (F614) as well as various Shigella $\mathrm{R} 1$ and R4 mutants did not stimulate the formation of CA antibodies after injection of heated cell suspensions. Previous genetic investigations have shown that the $\mathrm{S} / \mathrm{R}$ mutation of $E$. coli $\mathrm{F} 614$ concerns a gene of the $r f a$ cluster (20). Since R1 strains like $E$. coli $\mathrm{F} 470$, which are defective in the hislinked $r f b$ regions, are immunogenic with regard to CA, it was postulated that the kind of S/ $\mathrm{R}$ mutation leading to the $\mathrm{R} 1$ phenotype might be of importance for the expression of CA immunogenicity. Therefore, a more detailed investigation of the above-mentioned Shigella rough mutants was carried out to determine the nature of the $S / R$ mutation and its possible relationship to $\mathrm{CA}$ immunogenicity.

The results of the genetic experiments confirmed earlier findings (20) with $E$. coli F614; namely, that its rough phenotype is caused by mutation of an rfa gene involved in the translocation of O-specific chains onto the core. As shown here, the defective allelic region can be cotransduced with $p y r E$ together with $r f a$ genes determining the $\mathrm{R} 1$ core synthesis.

To our knowledge there is presently no information on gene loci in Shigella comparable to the rfa genes in Salmonella (22) and E. coli (20). The transduction experiments described here with smooth and rough Shigella strains have demonstrated that in Shigella, too, the core synthesis is directed by a cluster of genes ( $r f a)$ closely linked to $p y r E$. It is remarkable that the frequency of cotransduced $r f a$ genes from Shigella is lower than from $E$. coli (Table 4). This might suggest that the pyrE gene and the $r f a$ cluster are closer linked in $E$. coli than in Shigella.

The results of transduction and conjugation experiments with two CA non-immunogenic Shigella rough mutants (F3153 and F3161) suggest that in these strains, as in $E$. coli F614, the translocation of O-chains onto the core is blocked by a mutation of a pyrE-linked $r f a$ gene. This gene should be called $r f a L$ according to the designation of the corresponding Salmonella gene equivalent (22).

Moreover, genetic transfer experiments have revealed that there exists a close connection between CA immunogenicity of the bacterial cells and the function of the $r f a L$ gene. This relationship becomes clear considering recent findings to the effect that CA in CA-immunogenic strains is associated with the LPS molecule (13). The association between CA and LPS accounts for CA immunogenicity of the respective strains. It is conceivable that the $r f a L$ gene product, which is involved in the translocation of $\mathrm{O}$ and $\mathrm{T} 1$ chains onto the core (22), also participates in the enzymatic transfer of CA onto the LPS core of CA-immunogenic strains.

The participation of LPS genes in CA synthesis $(r f e ; 9,10)$ and in the expression of its immunogenicity $(r f a L)$ suggests that sugars are the main constituents of this antigen. This assumption was recently corroborated by the finding that CA is a heteropolymer of D-glucosamine and D-mannosamine uronic acid, partly esterified by palmitic acid (D. Männel and H. Mayer, manuscript in preparation).

The results of the present investigation suggest that CA antibodies will be elicited by those rough mutants which are blocked in O-chain synthesis and which have a complete core (like $\mathrm{R} 1, \mathrm{R} 4$, or K-12) capable of accepting the CA determinant. In contrast, rough mutants with the complete R2, R3, or Salmonella Ra core, which are also defective in O-chain synthesis $\left(r f b^{-}\right)$, fail to evoke CA antibodies when heated cell suspensions are used for immunization 
(11). One may, therefore, assume that these core types are not suitable for appropriate association with CA. Interestingly, these core types contain a common characteristic constituent, namely, $N$-acetyl-D-glucosamine, in their core oligosaccharides $(7,18,19)$ and differ in this respect from the other known core types such as $\mathrm{R} 1, \mathrm{R} 4$, and $\mathrm{K}-12$ which lack this sugar $(19,21)$. Possibly, the absence of glucosamine in the core oligosaccharide plays an important role for its acceptor properties for $\mathrm{CA}$ and thus for $\mathrm{CA}$ immunogenicity of whole cells.

\section{ACKNOWLEDGMENTS}

We are greatly indebted to B. A. D. Stocker, Stanford, Calif., for supplying us with phage P1kc and S. Hofmann, Robert-Koch-Institut, D-1000 Berlin, for supplying us with the Shigella type strains.

The excellent technical assistance of U. Fischer, A. Gutmann, and B. Straub is gratefully acknowledged.

\section{ADDENDUM IN PROOF}

With regard to the mapping of Shigella rfa genes we became aware of a recent study by $\mathrm{C}$. Godard and E. Hannecart-Pokorni (Arch. Int. Phys. Biochem. 83:20-21, 1975) in which the $R$ mutation site affecting the LPS core synthesis of an $S$. flexneri rough mutant was determined to be located near the $m t l$ region. This is in accordance with our observations that Shigella rfa genes are closely linked to pyrE, which in turn is situated near the $m t l$ genes.

\section{LITERATURE CITED}

1. Adams, M. H. 1959. Bacteriophages, p. 461-469. Interscience Publishers, Inc., New York.

2. Dmitriev, B. A., L. V. Backinowsky, V. L. Lvov, N. K. Kochetkov, and I. L. Hofman. 1975. Somatic antigen of Shigella dysenteriae type 3. Structural features of specific polysaccharide chain. Eur. J. Biochem. 50:539-547.

3. Galanos, C., O. Laderitz, and O. Westphal. 1969. A new method for extraction of $R$ lipopolysaccharides. Eur. J. Biochem. 9:245-249.

4. Hirschfeld, J. 1960. Immunoelectrophoresis procedure and application to the study of group-specific variations in sera. Sci. Tools (LKB, Stockholm) 7:18-25.

5. Kunin, C. M., M. V. Beard, and N. E. Halmagyi. 1962 Evidence for a common hapten associated with endotoxin fractions of $E$. coli and other Enterobacteriaceae. Proc. Soc. Exp. Biol. Med. 111:160-166.

6. Lederberg, J. 1950. Isolation and characterization of biochemical mutants of bacteria. Methods Med. Res. 3:5-22.

7. Lüderitz, O., O. Westphal, A. M. Staub, and H. Nikaido. 1971. Isolation and chemical and immunological characterization of bacterial lipopolysaccharides p. 145-224. In G. Weinbaum, S. Kadis, and S. J. Ajl (ed.), Microbial toxins, vol. 4. Academic Press Inc., New York.

8. Măkelă, P. H., M. Jahkola, and O. Laderitz. 1970. A new gene cluster rfe concerned with the biosynthesis of Salmonella lipopolysaccharide. J. Gen. Microbiol. 60:91-106.

9. Makelă, P. H., and H. Mayer. 1974. Participation of lipopolysaccharide genes in the determination of the enterobacterial common antigen: analysis in Salmonella groups $B$ and $C_{1}$. J. Bacteriol. 119:765-770.

10. Makela, P. H., H. Mayer, H. Y. Whang, and E. Neter. 1974. Participation of lipopolysaccharide genes in determination of the enterobacterial common antigen: analysis of $\mathbf{R}$ mutants of Salmonella minnesota. J. Bacteriol. 119:760-764.

11. Mayer, H., and G. Schmidt. 1971. Hämagglutinine gegen ein gemeinsames Enterobakteriaceen-Antigen in E. coli R1-Antiseren. Zentralbl. Bakteriol. Parasitenkd. Infektionskr. Hyg. Abt. 1 Orig. 216:299-313.

12. Mayer, H., and G. Schmidt. 1973. The occurrence of three different lipopolysaccharide cores in Shigella and their relationship to known enterobacterial core types. Zentralbl. Bakteriol. Parasitenkd. Infektionskr. Hyg. Abt. 1 Orig. Reihe A 224:345-354.

13. Mayer, H., G. Schmidt, H. Y. Whang, and E. Neter. 1972. Biochemical basis of the immunogenicity of the common enterobacterial antigen. Infect. Immun. 6:540-544.

14. Sawandeker, J. S., H. J. Sloneker, and A. Jeans. 1967. Quantitative determination of monosaccharides as their alditol acetates by gas-liquid chromatography. Anal. Chem. 37:1602-1604.

15. Scheidegrer, J. J. 1955. Une micro-méthode de l'immuno-electrophorèse. Int. Arch. Allergy Appl. Immunol. 7:103-110.

16. Schlecht, S., and O. Westphal. 1966. Wachstum und Lipopolysaccharid-Gehalt von Salmonellen bei Züchtung auf Agarnährböden. Zentralbl. Bakteriol. Parasitenkd. Infektionskr. Hyg. Abt. 1 Orig. 200:241259.

17. Schmidt, G. 1973. Genetical studies on the lipopolysaccharide structure of Escherichia coli K-12. J. Gen. Microbiol. 77:151-160.

18. Schmidt, G., I. Fromme, and H. Mayer. 1970. Immunochemical studies on core lipopolysaccharides of Enterobacteriaceae of different genera. Eur. J. Biochem. 14:357-366.

19. Schmidt, G., B. Jann, and K. Jann. 1969. Immunochemistry of $\mathrm{R}$ lipopolysaccharides of Escherichia coli. Different core regions in the lipopolysaccharides of $O$ group 8. Eur. J. Biochem. 10:501-509.

20. Schmidt, G., B. Jann, and K. Jann. 1970. Studies on R mutants with an incomplete core, derived from $E s c h$ erichia coli O8:K27. Eur. J. Biochem. 16:382-392.

21. Schmidt, G., B. Jann, and K. Jann. 1974. Genetic and immunochemical studies on Escherichia coli O14:K7:H' ${ }^{-}$. Eur. J. Biochem. 42:303-309.

22. Stocker, B. A. D., and P. H. Makela. 1971. Genetical aspects of biosynthesis and structure of Salmonella lipopolysaccharide, p. 396-433. In G. Weinbaum, S. Kadis, and S. J. Ajl (ed.), Microbial toxins, vol. 4. Academic Press Inc., New York.

23. Watson, G., and K. Paigen. 1971. Isolation and characterization of an Escherichia coli bacteriophage requiring cell wall galactose. J. Virol. 8:669-674.

24. Whang, H. Y., H. Mayer, G. Schmidt, and E. Neter. 1972. Immunogenicity of the common enterobacterial antigen produced by smooth and rough strains. Infect. Immun. 6:533-539.

25. Whang, H. Y., and E. Neter. 1967. Further studies on effect of endotoxin on antibody response of rabbit to common antigen of Enterobacteriaceae. J. Immunol. 98:948-957. 